\title{
Head Kidney Transcriptome Analysis and Characterization for the Sub-Antarctic Notothenioid Fish Eleginops maclovinus
}

\author{
Danixa Martínez ${ }^{1,2,3, *,+}$, Juan Pablo Pontigo ${ }^{1, *,+}$, Francisco J. Morera ${ }^{4}$, Alejandro. Yañéz ${ }^{5,6}$ \\ and Luis Vargas-Chacoff $1,3, *$ \\ 1 Instituto de Ciencias Marinas y Limnológicas, Universidad Austral de Chile, Valdivia 5090000, Chile \\ 2 Escuela de Graduados, Programa de Doctorado en Ciencias de la Acuicultura, Universidad Austral de Chile, \\ Av. Los Pinos s/n Balneario Pelluco, Puerto Montt 5480000, Chile \\ 3 Centro Fondap de Investigación de Altas Latitudes (IDEAL), Universidad Austral de Chile, \\ Valdivia 5090000, Chile \\ 4 Instituto de Farmacología y Morfofisiología, Universidad Austral de Chile, Valdivia 5090000, Chile; \\ fjmorera@gmail.com \\ 5 Instituto de Bioquímica y Microbiología, Universidad Austral de Chile, Valdivia 5090000, Chile; \\ ayanez@uach.cl \\ 6 Interdisciplinary Center for Aquaculture Research (INCAR), Concepción 4030000, Chile \\ * Correspondence: danixapamela@gmail.com (D.M.); jppontigo@gmail.com (J.P.P.); \\ luis.vargas@uach.cl (L.V.-C.); Tel.: +56-63-221648 (L.V.-C.); Fax: +56-63-221315 (L.V.-C.) \\ + These authors contributed equally to this work.
}

Received: 2 January 2018; Accepted: 16 January 2018; Published: 25 January 2018

\begin{abstract}
This study describes de novo transcriptome sequencing and annotation analyses for the head kidney of the sub-Antarctic notothenioid fish Eleginops maclovinus, a sister group of the Antarctic notothenioid fish clade. Moreover, E. maclovinus is one of the most eurythermal and euryhaline representatives of the Notothenioidei suborder. RNA-seq data were generated by the 454 GS Junior system, resulting in 11,207 contigs that were then assembled by the Genomic Workbench CLC software. The transcriptome was annotated by BLASTing each sequence against the universal, non-redundant NCBI database (National Center for Biotechnology Information) using the AUSTRAL-omics computer cluster. A significant number of transcripts related to innate and adaptive immunity were found in the sequences, which could be used as references in future immunological studies in E. maclovinus.
\end{abstract}

Keywords: Eleginops maclovinus; transcriptome; notothenioid; immunity; head kidney

\section{Introduction}

Eleginops maclovinus (Valenciennes 1830) is a notothenioid (Perciformes) endemic to the temperate and sub-Antarctic waters of South America. This fish is the only representative of the Eleginopsidae (Osteichthyes) family within the Notothenioidei suborder. Regarding phylogeny, the Eleginopsidae, Pseudaphritidae, and Bovichtidae families emerged before a severe decrease in water temperature approximately 24 million years ago [1]. Therefore, these families are known as non-Antarctic Notothenioidei that diverged early from the main notothenioid lineage. These families also never established on the Antarctic shelf [2], either due to a lack of crucial biochemical and physiological adaptations to cold (e.g., antifreeze glycoproteins), the lack of dispersal potential (e.g., small eggs and larval stages with reduced mobility), or the dependence on estuarine environments that are absent in the Antarctic [3]. Meanwhile, the Antarctic fish lack a common cellular defense mechanism called the heat shock response (HSR) by molecular chaperones [4], developing a cardiovascular system with 
modifications that involve large-bore blood vessels, large blood volumes; and large hearts with high content of mitochondria [5].

Genetic analyses of Antarctic fish are possible due to an availability of cDNA sequence libraries for various species, including Dissostichus mawsoni (Nototheniidae) [6], Harpagifer antarcticus (Harpagiferidae) [7], Chionodraco hamatus (Channichthyidae) [8], Trematomus bernacchii [9,10], Pagothenia borchgrevinki [11], Chaenocephalus aceratus (Channichthyidae), Notothenia coriiceps, and Pleuragramma antarcticum (Nototheniidae) [12,13]. To date, relatively little sequence information is available for E. maclovinus [2], despite the physiological characteristics that consider it an eurythermic, euryhaline and stenobatic species [14], with a hermaphrodite type of reproduction (unique among the notothenioids) [15] and with a relevant participation in the transmission of diseases that affect aquaculture as the Piscirickettsiosis [16]. This report describes the de novo assembly and annotation of the E. maclovinus head kidney transcriptome, providing a new source of genetic information that can be used in future studies dealing with the immunological response of notothenioids.

\section{Results}

Functional annotation against the Gene Ontology database revealed transcripts involved in cellular components, molecular functions, and biological processes (Figure 1). Among the biological processes, several transcripts were found with functions in the innate and adaptive immune response of E. maclovinus, representing a significant advance in respect with the genomic data available for this species (Table 1). The high prevalence of immune-related transcripts in the E. maclovinus head kidney is in line with previous reports from T. bernacchii [10]. The head kidney has been reported a primary lymphoid organs in the bony fishes that functions as lymphocyte precursor tissue responsible for the generation as well as maturation of B cells, and the generation of T-cell progenitor cells that migrate to the thymus throughout life [17]. The head kidney in fish also has endocrine functions, including cortisol synthesis by interrenal cells and catecholamine synthesis by chromaffin cells. Therefore, this tissue presents functions analogous to the mammalian adrenal gland [18].

Table 1. List of annotated Gene Ontology (GO) biological processes relevant to the innate and/or adaptive immune systems, detailing the number of corresponding annotated contigs in the Eleginops maclovinus transcriptome.

\begin{tabular}{cc}
\hline GO Category & Description \\
\hline GO:0002376 & H-2 class ii histocompatibility antigen gamma chain-like \\
GO:0045087 & Tyrosine-protein kinase fgr isoform $\times 1$ \\
GO:0002755 & Ubiquitin-40s ribosomal protein s27a \\
GO:0045087 & Af280815_1calmodulin partial \\
GO:0006955 & Major histocompatibility class i receptor \\
GO:0006955 & Tumor necrosis factor ligand superfamily member 13b \\
GO:0006054 & Macrophage colony-stimulating factor 1 receptor 2-like \\
GO:0006055 & Ectodysplasin splice variant-8 partial \\
GO:0002474 & Mhc class i alpha partial \\
GO:0001916 & Mhc class i antigen \\
GO:0006955 & Invariant chain-like protein 14-1 \\
GO:0002504 & Mhc class ii antigen beta chain \\
GO:0006355 & Paired amphipathic helix protein sin3a \\
GO:0002376 & G-protein coupled receptor 183-like \\
GO:0045087 & Actin-related protein 3 \\
GO:0045087 & Cell division control protein 42 homolog \\
GO:0006954 & Toll-like receptor 1 \\
GO:0045087 & Catenin beta-1-like \\
GO:0006954 & Toll-like receptor 8 \\
\hline
\end{tabular}




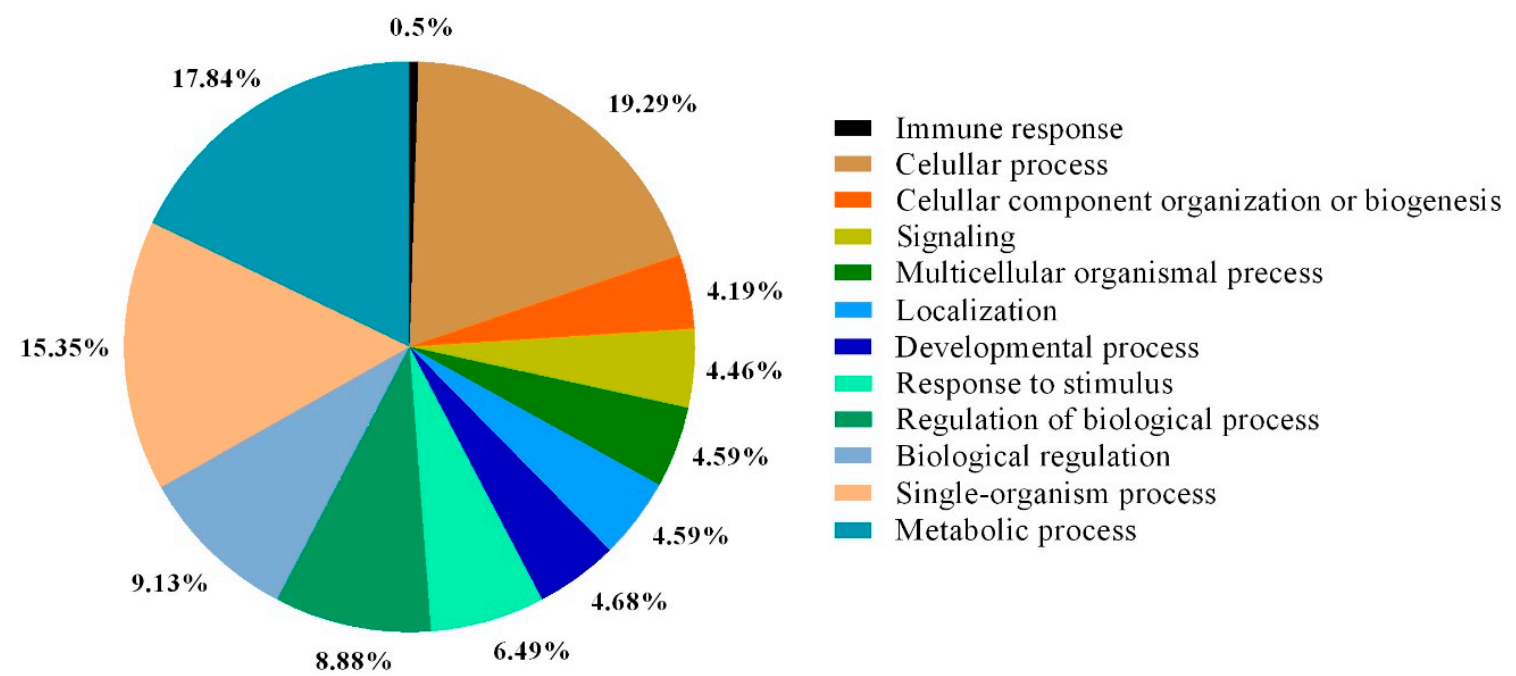

Figure 1. Functional Gene Ontology annotation of the Eleginops maclovinus head kidney transcriptome revealed transcripts involved in biological processes.

\section{Materials and Methods}

\subsection{Animal Specimens}

Eleginops maclovinus specimens were collected with nets from the wild and transferred to the Calfuco Coastal Laboratory (Faculty of Science, Universidad Austral de Chile, Valdivia, Chile). Fish were acclimated for four weeks to seawater (32 psu, $1085 \mathrm{mOsm} \mathrm{kg}{ }^{-1}$ ) in $500 \mathrm{~L}$, flow-through system ponds at a stocking density of $3.1 \mathrm{~kg} \mathrm{~m}^{-3}$ and under natural photoperiod and temperature $\left(12 \pm 0.5^{\circ} \mathrm{C}\right)$ conditions, per methodology described by Vargas-Chacoff et al. [19]. Fish were fed using commercial Nutreco Defense 100 dry pellets (Skretting, Stavanger, Norway) containing 48\% protein, $22 \%$ fat, $13.5 \%$ carbohydrates, $8 \%$ humidity, and $8.5 \%$ ash. Fish were fed once daily at a ratio of $1 \%$ body weight. All experiments complied with animal use guidelines established by the National Commission for Scientific and Technological Research of Chile (CONICYT) and the Universidad Austral de Chile.

\subsection{RNA Isolation, Library Construction, and Sequencing}

Fish were anaesthetized with a lethal dose of 2-fenoxietanol $\left(1 \mathrm{~mL} \mathrm{~L}^{-1}\right)$, weighed, measured, and dissected for sample collection. The head kidney was aseptically removed and stored at $-80^{\circ} \mathrm{C}$. All steps involving massive cDNA sequencing were performed using a GS Junior Titanium Series System (Roche, Basel, Switzerland) at the AUSTRAL-omics Laboratory (Universidad Austral of Chile) following the manufacturer's protocols. In detail, total RNA was extracted from the head kidney with the NucleoSpin ${ }^{\circledR}$ RNA kit (Macherey-Nagel, Dueren, Germany). Total RNA quantity and quality were evaluated spectrophotometrically (A260) using the NanoDrop ND-1000 spectrophotometer (NanoDrop Technologies, Waltham, MA, USA) and Agilent 2100 Bioanalyzer (Agilent Technologies, Santa Clara, CA, USA), respectively.

Head kidney mRNA was isolated with the PolyATtract kit ${ }^{\circledR}$ mRNA Isolation System III (Promega, Madison, WI, USA), and mRNA concentration was determined using the Quant-iT ${ }^{\mathrm{TM}}$ RiboGreen $^{\circledR}$ RNA Assay kit. The cDNA library was constructed following the "Rapid cDNA library preparation" protocol recommended by Roche. This protocol begins with a minimal amount of mRNA (300 ng). Then, mRNA samples were fragmented with $\mathrm{ZnCl}$ to an optimal range of 200 to 1200 base pairs before the subsequent synthesis of double-stranded cDNA (Synthesis System kit, Roche) and removal of small fragments. The library was quantified by fluorescence, obtaining an approximate concentration of $6.4^{8}$ molecules DNA/ $\mu \mathrm{L}$. The Roche-recommended protocol advised preparing a working dilution of $1 \times 10^{7}$ DNA molecules DNA/ $\mu$ L to ensure successful emulsion PCR. Therefore, the working 
solution was prepared using $7.3 \mu \mathrm{L}$ of library molecules in $492.7 \mu \mathrm{L}$ of TE buffer. This solution $(10 \mu \mathrm{L})$ was then used for emulsion PCR following the protocol outlined in the emPCR Amplification Method Manual-Lib-L, GS Junior Titanium Series (ed. March 2012), which resulted in 10\% bead recovery. The amplified cDNA for each microsphere was pyrosequenced in a 454 GS Junior System (Roche). The raw data were processed from a series of individual images taken for each well of the sequenced plate. The data were extracted and then quantified and normalized with control DNA microspheres. The results generated by Roche 454 sequencing are show in Table 2.

Table 2. Roche 454 sequencing results for the head kidney transcriptome of Eleginops maclovinus.

\begin{tabular}{|c|c|}
\hline \multicolumn{2}{|c|}{ A. Number of Obtained Readings } \\
\hline Raw Wells & 291,469 \\
\hline Key Pass Wells & 281,128 \\
\hline Passed Filter Wells & 208,809 \\
\hline Total Bases & $95,309,200$ \\
\hline \multicolumn{2}{|c|}{ B. Sizes of the Obtained Sequences } \\
\hline Length Average & 456 \\
\hline Longest Read Length & 1173 \\
\hline Shortest Read Length & 40 \\
\hline Median Read Length & 500 \\
\hline Mode Read Length & 542 \\
\hline
\end{tabular}

\subsection{De Novo Transcriptome Assembly, Identification of Protein Coding Region, and Annotation}

Regarding bioinformatics analysis, sequences were filtered using the prinseq-lite.pl software [20], with different cut-off parameters at both ends of each sequence. The cut-off values are given by adapters or for low quality existing at the ends of the readings. Furthermore, average quality filters were applied to discard reads that did not meet minimum threshold cut-off values. De novo transcriptome assembly was performed using the CLC Genomic Workbench software 7.0.3 and the transcriptome was annotated by BLASTing each sequence against the universal, non-redundant NCBI database (National Center for Biotechnology Information) using the AUSTRAL-omics computer cluster. This step consequently allowed for functional annotation against the Gene Ontology database using the Blast2GO software [21]. Annotation was performed for transcripts assembled by the Genomic Workbench CLC software, as well as for unassembled reads to identify low-abundance transcripts that could only be sequenced once. The results of bioinformatics analyses are show in Table 3. Raw sequencing data have been deposited in the NCBI SRA database (Sequence Read Archive) with the accession ID SRP129851.

Table 3. Bioinformatics analysis results for the head kidney transcriptome of Eleginops maclovinus.

\begin{tabular}{ccc}
\hline & Assembled Transcripts & Unassembled Reads \\
\hline Number of transcripts & 5088 & 6119 \\
Base pairs & $2,398,375$ & $1,780,104$ \\
Annotated with "nr" & 2000 & 1602 \\
Not annotated with "nr" & 3088 & 4517 \\
\hline
\end{tabular}

\section{Conclusions}

The obtained E. maclovinus transcriptome represents a significant advancement in the genomic data available for this species. Papetti et al. [2] assessed the GenBank information for E. maclovinus, finding 125 nucleotide entries ( 71 mitochondrial, 54 nuclear, with 10 microsatellite markers among these), 124 protein entries (78 mitochondrial, 46 nuclear), and 38 popsets (phylogenetic studies). The sequences reported by the present study provide a new source of genetic information that can be 
used in future studies dealing with immunological response of E. maclovinus and other notothenioids Antarctic at a comparative level.

Acknowledgments: This work was financed by the Fondap-Ideal Grant No. 15150003, Fondecyt Regular Grant No. 1160877, and the Dirección de Investigación-Desarrollo (DID, Universidad Austral de Chile). We acknowledge Carlos Loncoman (University of Melbourne) for his help handling the sequences and submission process to GenBank. Danixa Martínez was funded by the Comisión Nacional de Investigación Científica y Tecnológica (CONICYT) through a national doctoral scholarship.

Author Contributions: D.M., J.P.P. and L.V.-C. conceived and designed the experiments; J.P.P. performed the experiments; D.M. and J.P.P. analyzed the data; F.J.M., A.Y. and L.V.-C. contributed reagents/materials/analysis tools; D.M. and J.P.P. wrote the paper.

Conflicts of Interest: The authors declare that they have no competing interests

\section{References}

1. Near, T.J. Estimating divergence times of notothenioid fishes using a fossil-calibrated molecular clock. Antarct. Sci. 2004, 16, 37-44. [CrossRef]

2. Papetti, C.; Windisch, H.S.; La Mesa, M.; Lucassen, M.; Marshall, C.; Lamare, M.D. Non-Antarctic notothenioids: Past phylogenetic history and contemporary phylogeographic implications in the face of environmental changes. Mar. Genom. 2016, 25, 1-9. [CrossRef] [PubMed]

3. La Mesa, M.; Caputo, V.; Eastman, J.T. Some reproductive traits of the Tristan klipfish, Bovichtus diacanthus (Carmichael 1819) (Notothenioidei: Bovichtidae) from Tristan da Cunha (South Atlantic). Polar Biol. 2010, 33, 337-346. [CrossRef]

4. Hofmann, G.E.; Lund, S.G.; Place, S.P.; Whitmer, A.C. Some like it hot, some like it cold: The heat shock response is found in New Zealand but not Antarctic notothenioid fishes. J. Exp. Mar. Bio. Ecol. 2005, 316, 79-89. [CrossRef]

5. Beers, J.M.; Jayasundara, N. Antarctic notothenioid fish: what are the future consequences of "losses" and "gains" acquired during long-term evolution at cold and stable temperatures? J. Exp. Biol. 2015, 218, 1834-1845. [CrossRef] [PubMed]

6. Chen, Z.; Cheng, C.-H.C.; Zhang, J.; Cao, L.; Chen, L.; Zhou, L.; Jin, Y.; Ye, H.; Deng, C.; Dai, Z.; et al. Transcriptomic and genomic evolution under constant cold in Antarctic notothenioid fish. Proc. Natl. Acad. Sci. USA 2008, 105, 12944-12949. [CrossRef] [PubMed]

7. Thorne, M.A.S.; Burns, G.; Fraser, K.P.P.; Hillyard, G.; Clark, M.S. Transcription profiling of acute temperature stress in the Antarctic plunderfish Harpagifer antarcticus. Mar. Genom. 2010, 3, 35-44. [CrossRef] [PubMed]

8. Coppe, A.; Agostini, C.; Marino, I.A.M.; Zane, L.; Bargelloni, L.; Bortoluzzi, S.; Patarnello, T. Genome evolution in the cold: Antarctic icefish muscle transcriptome reveals selective duplications increasing mitochondrial function. Genome Biol. Evol. 2013, 5, 45-60. [CrossRef] [PubMed]

9. Huth, T.J.; Place, S.P. De novo assembly and characterization of tissue specific transcriptomes in the emerald notothen, Trematomus bernacchii. BMC Genom. 2013, 14, 1-13. [CrossRef] [PubMed]

10. Gerdol, M.; Buonocore, F.; Scapigliati, G.; Pallavicini, A. Analysis and characterization of the head kidney transcriptome from the Antarctic fish Trematomus bernacchii (Teleostea, Notothenioidea): A source for immune relevant genes. Mar. Genom. 2015, 20, 13-15. [CrossRef] [PubMed]

11. Bilyk, K.T.; Cheng, C.H.C. Model of gene expression in extreme cold-Reference transcriptome for the high-Antarctic cryopelagic notothenioid fish Pagothenia borchgrevinki. BMC Genom. 2013, 14, 634. [CrossRef] [PubMed]

12. Shin, S.C.; Kim, S.J.; Lee, J.K.; Ahn, D.H.; Kim, M.G.; Lee, H.; Lee, J.; Kim, B.K.; Park, H. Transcriptomics and comparative analysis of three Antarctic Notothenioid fishes. PLoS ONE 2012, 7, 1-9. [CrossRef] [PubMed]

13. Shin, S.C.; Ahn, D.H.; Kim, S.J.; Pyo, C.W.; Lee, H.; Kim, M.K.; Lee, J.; Lee, J.E.; Detrich, H.W.; Postlethwait, J.H.; et al. The genome sequence of the Antarctic bullhead notothen reveals evolutionary adaptations to a cold environment. Genome Biol. 2014, 15, 468. [CrossRef] [PubMed]

14. Pequeño, G. The geographical distribution and taxonomic arrangement of south american notothenhd fishes (Osteichthyes, Notothenhdae). Bol. Soc. Biol. Concepc. 1989, 183-200.

15. Brickle, P.; Laptikhovsky, V.; Arkhipkin, A. Reproductive strategy of a primitive temperate notothenioid Eleginops maclovinus. J. Fish Biol. 2005, 66, 1044-1059. [CrossRef] 
16. Contreras-Lynch, S.; Olmos, P.; Vargas, A.; Figueroa, J.; González-Stegmaier, R.; Enríquez, R.; Romero, A. Identification and genetic characterization of Piscirickettsia salmonis in native fish from southern Chile. Dis. Aquat. Organ. 2015, 115, 233-244. [CrossRef] [PubMed]

17. Soulliere, C.; Dixon, B. Immune System Organs of Bony Fishes; Elsevier Ltd.: Amsterdam, The Netherlands, 2017; ISBN 9780128096338.

18. Gallo, V.P.; Civinini, A. Survey of the Adrenal Homolog in Teleosts. Int. Rev. Cytol. 2003, 230, 89-187. [PubMed]

19. Vargas-Chacoff, L.; Moneva, F.; Oyarzún, R.; Martínez, D.; Muñoz, J.L.P.; Bertrán, C.; Mancera, J.M. Environmental salinity-modified osmoregulatory response in the sub-Antarctic notothenioid fish Eleginops maclovinus. Polar Biol. 2014, 37, 1235-1245. [CrossRef]

20. Schmieder, R.; Edwards, R. Quality control and preprocessing of metagenomic datasets. Bioinformatics 2011, 27, 863-864. [CrossRef] [PubMed]

21. Conesa, A.; Götz, S.; García-Gómez, J.M.; Terol, J.; Talón, M.; Robles, M. Blast2GO: A universal tool for annotation, visualization and analysis in functional genomics research. Bioinformatics 2005, 21, 3674-3676. [CrossRef] [PubMed]

(C) 2018 by the authors. Licensee MDPI, Basel, Switzerland. This article is an open access article distributed under the terms and conditions of the Creative Commons Attribution (CC BY) license (http://creativecommons.org/licenses/by/4.0/). 